\title{
Erratum to: Radiological radio-carpal and mid-carpal motion after operative treatment of dorsal radio-carpal fracture dislocations
}

\author{
Jürgen Oberladstätter $\cdot$ Rohit Arora $\cdot$ \\ Christian Dallapozza $\cdot$ Vinzenz Smekal • \\ Christian Kammerlander • Martin Lutz
}

Published online: 9 March 2012

(c) Springer-Verlag 2012

Erratum to: Arch Orthop Trauma Surg (2010)

130:77-81

DOI 10.1007/s00402-009-0902-0

The original article has been published with incorrect corresponding author information. The corresponding author and e-mail address for the article should be as given below

Christian Kammerlander

e-mail: christian.kammerlander@uki.at

The online version of the original article can be found under doi:10.1007/s00402-009-0902-0.

J. Oberladstätter · R. Arora · C. Dallapozza · V. Smekal ·

C. Kammerlander $(\bowtie) \cdot$ M. Lutz

Department of Trauma Surgery and Sports Medicine,

Medical University of Innsbruck, Anichstrasse 35,

6020 Innsbruck, Austria

e-mail: christian.kammerlander@uki.at

J. Oberladstätter

e-mail: juergen.oberladstaetter@i-med.ac.at

R. Arora

e-mail: rohit.arora@uki.at

C. Dallapozza

e-mail: christian.dallapozza@i-med.ac.at

V. Smekal

e-mail: vinzenz.smekal@uki.at

M. Lutz

e-mail: martin.lutz@i-med.ac.at 